\title{
A atenção em Saúde M ental em municípios de pequeno e médio portes: ressonâncias da reforma psiquiátrica
}

\author{
M ental Healthcare in small and medium-sized cities: \\ resonance of the psychiatric reform
}

Cristina Amélia Luzio ${ }^{1}$

Solange L'Abbate ${ }^{2}$

${ }^{1}$ Departamento de Psicologia Clínica, FaculdadedeCiênciase Letras de Assis, UNESP. Av. Dom Antonio 2100, Jardim Universitário. 19806-900 Assis SP. caluzio@assis.unesp.br ${ }^{2}$ Departamento de M edicina Preventiva e Social, Faculdade de Ciências M édicas, UNICAMP.
Abstract From the analysis of the national $M$ ental $\mathrm{H}$ ealth policy, formulated in the past years, and from the experiences developed after 1987, it is sought to: understand how Brazilian Health System has contributed to the development of the psychiatric reform in towns; verify how the assistance offered in those towns is making the psychiatric reform principles feasible as well as improving the users' living conditions; and research the role of the workers and managers in the construction of new care practices in $M$ ental $\mathrm{H}$ ealth. The analysis of the discursive practices point out that the various social segments involved in M ental $\mathrm{H}$ ealth have acquaintance with the principles and proposals of the psychiatric reform. However, themunicipal administrations do not thoroughly take on the proposals of the $\mathrm{H}$ ealth M inistry to this field, under the allegation of lack of financial funds to meet the demands. The users and their relatives have gradually assumed the new intervention proposals, but the mechanisms of participation and popular organization are still incipient. Lastly, it is important to stress that for an effective consolidation of thecurrent psychiatricreform proposals, theremust be, among other actions, more commitment by the managers as far as $M$ ental $H$ ealth is concerned, more investments in multi-professional teams, encouragement to the organization and the users' and relatives' participation and integration of health devices, social assistance and the culture existing in towns. Key words Psychiatric reform, Psychosocial attention, M ental health, Collective health
Resumo A partir da análiseda Política N acional de Saúde M ental formulada nos últimos anos e das experiências desenvolvidas após 1987 no país, procura-se compreender como o Sistema Ú nico de Saúde tem contribuído ao avanço da reforma psiquiátrica nos municípios; verificar como a assistência oferecida nesses municípios está viabilizando os princípios da reforma psiquiátrica ea melhora das condi ções de vida dos usuários, bem como pesquisar o papel dos trabal hadores e gestores na construção de novas práticas decuidado em SaúdeM ental. A análise das práticas discursivas aponta que os vários segmentos sociais envolvidos na Saúde M ental conhecem os princípios e propostas da reforma psiquiátrica. No entanto, as gestões municipais não assumem integralmente as propostas do M inistério da Saúde para a área, sob a alegação de falta de recursos financeiros para a contrapartida exigida. Os usuários efamiliares têm aos poucos assumido as novas propostas de intervenção, mas os mecanismos de participação e organização popular ainda são inci pientes. Por fim, deve-se destacar que, para uma efetiva consolidação das propostas atuais da reforma psiquiátrica, é ne cessário um maior compromisso dos gestores com a atenção em Saúde M ental, maior investimento nas equipes multiprofissionais, o estímulo à organização e à participação dos usuários e familiares e a integralidade dos dispositivos de saúde, deassistência social e de cultura existentes nas cidades.

Palavras-chave Reforma psiquiátrica, Atenção psicossocial, Saúde mental, Saúde coletiva 
Consideraçõesiniciais:

a inserção da Saúde M ental no SUS

A partir da implantação do Sistema Ú nico deSaúde (SUS), os municípios buscaram viabilizar, em todos os setores da saúde, os direitos constitucionais de seus usuários. Muitos passaram a desenvolver ações substitutivas na Saúde M ental. Em artigo recentemente publicado ${ }^{1}$, analisaram-se al gumas experiências exitosas no campo da Saúde M ental no Estado de São Paulo. No entanto, pouco seconhece acerca das ressonâncias da políticanacional deSaúde M ental na maioria dos municípios, em especial nos de pequeno e médio portes, cujos governos não se destacam enquanto gestores comprometidos com a melhoria das condições de vida da população e com a redução das desigualdades sociais.

Embora a maioria da população (51\%) resida nos $4 \%$ dos municípios com população acima de 100.000 habitantes, $96 \%$ possuem população inferior a 100.000 habitantes, sendo que $63 \%$ dos municípios brasileiros possuem população de até 20.000 habitantes. Portanto, o cotidiano das instituições de saúde nos pequenos territórios caracteriza a quase totalidade dos municípios brasileiros ${ }^{2}$.

No que se refere à atenção em Saúde M ental, os municípios de pequeno e médio portes em ge ral, a partir da criação do SUS, incluíram equipes de Saúde M ental nas Unidades Básicas de Saúde (UBS). Esse fato não significou que os municípios assumiam um projeto de Saúde M ental, pautado pelos princípios e diretrizes da reforma psiquiátrica. N a maioria das vezes, tais municípios procuraram dar conta de sua nova responsabilidade de cuidar de seus usuários essencialmente via internação psiquiátrica emedicação, reproduzindo apenas o modelo psiquiátrico hegemônico ${ }^{3}$.

Na década de 1990, o M inistério deSaúde(MS) passou a propor uma política de Saúde M ental a partir das experiências municipais inovadoras, associadas às reflexões e às propostas operadas pelo movimento da reforma psiquiátrica, possibilitando aos gestores, aos profissionais, aos usuários e à sociedade civil o conhecimento e 0 acesso a um novo projeto de atenção em Saúde M ental.

Nesse sentido, este estudo, que compõe a tese de doutorado da primeira autora, propôs-se a conhecer as ressonâncias das propostas do movimento da reforma psiquiátrica no que se refere às transformações nos campos teórico-conceitual, técnicoassistencial, político-jurídico e sociocultural, em municípios de pequeno e médio portes, tomando como realidade empírica as cidades de Cândido M ota e Assis, no interior do Estado de São Paulo. Ou seja, buscou identificar como a assistência em
Saúde M ental, oferecida por municípios de pequeno emédio portes, está viabilizando, deum lado, os princípios da reforma psiquiátrica e, de outro, a melhora das condições de vida dos usuários.

\section{Percurso metodológico}

0 estudo situa-se no campo das metodologias qualitativas, sendo quea escolha dos municípios deCândido Mota e Assis, considerados, respectivamente, de pequeno e médio portes e localizados na região oeste do Estado de São Paulo, não foi orientada por nenhum critério clássico de amostragem probabilística, mas por terem serviços de Saúde M ental estruturados e inseridos no sistema de saúde local.

Para conhecer a maneira como estão ocorrendo os avanços, as dificuldades e os entraves existentes na transformação das práticas manicomiais dos municípios estudados, foram utilizadas técnicas para a captação das informações, tais como: análise de textose documentos, bem como realização de entrevistas semi-estruturadas com participantes dos diversos segmentos sociais implicados com a Saúde M ental.

A partir dos aportes teóricos desenvolvidos por vários autores ${ }^{4-8}$, cujas produções são orientadas pelo método dialético, buscou-se captar os movimentos contraditórios e mutantes no processo de construção de novos modos e novas práticas de cuidado em Saúde M ental nos municípios estudados, notadamente no que se refere aos intercruzamentos das práticas discursivas relacionadas aos temas estudados.

A expressão "atenção psicossocial", aqui utilizada, defineo conjunto deações nos camposteóricos, éticos, técnicos, políticos esociais, aptosa constituírem um novo paradigma para as práticas em Saúde M ental. Enfim, ele compartilha da premissa de que a atenção psicossocial não é apenas mudança da assistência, mas um processo de transição paradigmática?.

Os temas investigados foram agrupados em categorias construídas a partir de uma articulação entre a produção dos autores acima citados e as extraídas dos textos, documentos e entrevistas, conforme apresenta o Q uadro 1.

Quanto aos entrevistados, todos possuíam mais de seis meses de envolvimento nos serviços de Saúde Mental pesquisados e, portanto, podem ser considerados atores sociais relevantes, capazes de contribuir para 0 enfrentamento dos desafios colocados a cada momento. Para facilitar a citação dos discursos dos participantes e proteger suas identidades, estes foram nomeados de acordo com o Quadro 2. 
Quadro 1. As categorias de análise: campos, definição e subtemas.

\begin{tabular}{|c|c|c|}
\hline campo & definição & subtemas \\
\hline $\begin{array}{l}\text { teórico- } \\
\text { conceitual }\end{array}$ & $\begin{array}{l}\text { Identificar e compreender a concepção de saúde- } \\
\text { doença-cura, os meios de trabalho e de } \\
\text { tratamento queque orientam os serviços de } \\
\text { Saúde M ental. }\end{array}$ & $\begin{array}{l}\text { Concepção de saúde/doença mental } \\
\text { Objetivos e meios de tratamento } \\
\text { Finalidade do tratamento e seus efeitos } \\
\text { terapêuticos e éticos } \\
\text { Referencial teórico e formação profissional }\end{array}$ \\
\hline $\begin{array}{c}\text { técnico- } \\
\text { assistencial }\end{array}$ & $\begin{array}{l}\text { Analisar a organização da rede de serviços como } \\
\text { espaços de produção de subjetividades, garantidos } \\
\text { por intermédio de novos equipamentos e diversas } \\
\text { ações e pela co-gestão dos usuários, trabalhadores } \\
\text { e população }\end{array}$ & $\begin{array}{l}\text { M odo de organização do serviço } \\
\text { Organização das ações no serviço } \\
\text { O trabalho em equipe } \\
\text { Fluxo do poder decisório e de execução do serviço } \\
\text { As ações no território }\end{array}$ \\
\hline $\begin{array}{l}\text { político- } \\
\text { jurídico }\end{array}$ & $\begin{array}{l}\text { Analisar a legislação (federal, estadual e } \\
\text { municipal) referente à doença mental, de modo } \\
\text { a permitir aos usuários o exercício dos direitos à } \\
\text { cidadania, acesso ao trabalho e à inclusão social }\end{array}$ & $\begin{array}{l}\text { Percepção das políticas de Saúde M ental estadual } \\
\text { e nacional } \\
\text { Leis, portarias, normas e diretrizes acerca da } \\
\text { atenção psicossocial. } \\
\text { Direitos dos usuários } \\
\text { Política local e a Saúde M ental }\end{array}$ \\
\hline sociocultural & $\begin{array}{l}\text { Identificar as práticas que objetivam as } \\
\text { mudanças da percepção da sociedade acerca da } \\
\text { doença mental, da loucura, da anormalidade e da } \\
\text { periculosidade do louco e dos serviços de Saúde } \\
\text { M ental }\end{array}$ & $\begin{array}{l}\text { Percepção da população acerca da doença mental } \\
\text { ações intersetoriais } \\
\text { Relação da população e os serviços } \\
\text { Participação popular e o controle social }\end{array}$ \\
\hline
\end{tabular}

Quadro 2. I dentificação dos participantes do estudo de acordo com sua representação e município de origem.

\begin{tabular}{|c|c|c|c|c|}
\hline Representantes & Cândido Mota & identificação & Assis & identificação \\
\hline Gestores & $\begin{array}{l}\text { Secretário M unicipal de Saúde } \\
\text { Coordenador de Saúde M ental } \\
\text { do Centro de Saúde }\end{array}$ & $\begin{array}{l}\mathrm{G} 1 \\
\mathrm{G} 2\end{array}$ & $\begin{array}{l}\text { Secretário M unicipal de Saúde } \\
\text { Articulador de Saúde M ental } \\
\text { da DIRVIII } \\
\text { Coordenador de Saúde M ental } \\
\text { do município } \\
\text { Coordenador dos Ambulatório } \\
\text { e CAPS }\end{array}$ & $\begin{array}{l}\mathrm{G} 1 \\
\mathrm{G} 2 \\
\mathrm{G} 3 \\
\mathrm{G} 4\end{array}$ \\
\hline Trabalhadores & $\begin{array}{l}\text { membro da equipe de apoio } \\
\text { assistente social } \\
\text { psicólogo } \\
\text { psiquiatra }\end{array}$ & $\begin{array}{l}\text { T1 } \\
\text { T2 } \\
\text { T3 } \\
\text { T4 }\end{array}$ & $\begin{array}{l}\text { membro da equipe de apoio } \\
\text { assistente social } \\
\text { psicólogo } \\
\text { psiquiatra }\end{array}$ & $\begin{array}{l}\text { T1 } \\
\text { T2 } \\
\text { T3 } \\
\text { T4 }\end{array}$ \\
\hline Usuários & $\begin{array}{l}\text { usuário } \\
\text { família } \\
\text { Representante dos usuários do } \\
\text { CM S }\end{array}$ & $\begin{array}{l}\text { U } 1 \\
\text { U } 2 \\
\text { U } 3\end{array}$ & $\begin{array}{l}\text { usuário } \\
\text { família } \\
\text { Representante dos usuários do } \\
\text { CM S }\end{array}$ & $\begin{array}{l}\text { U } 1 \\
\text { U } 2 \\
\text { U } 3\end{array}$ \\
\hline
\end{tabular}

\section{A (re) construção de duas situações singulares: os municípios estudados}

Os municípios de Cândido Mota e Assis localizam-seno oeste do Estado de São Paulo, na região do médio Valedo Paranapanema. 0 primeiro, fun- dado em 1923, tinha uma população, segundo o Censo de 2000, de 29.280 habitantes, sendo $91 \%$ residentes na zona urbana. Assis, por sua vez, fundado em 1905, possuía, segundo o mesmo documento, uma população de 87.251 habitantes, dos quais $95,6 \%$ vivem na zona urbana ${ }^{10}$. 
Os primórdios da assistência

em Saúde M ental nos municípios estudados

$\mathrm{Na}$ área da Saúde M ental, pode-se afirmar que na região de Assis, sede da antiga DIR VIII , o único atendimento público em Saúde M ental disponível à maioria da população até a década de 1980 era 0 da internação psiquiátrica. No entanto, os dois municípios nunca conviveram com a presença concreta de hospitais psiquiátricos. As internações dos usuários residentes nessas cidades sempre ocorreram em instituições localizadas em municípios de outras regiões, a uma distância de, no mínimo, setenta quilômetros.

No município de Cândido M ota, a assistência em Saúde M ental iniciou-se no começo da década de 1990, com a implantação do Sistema único de Saúde (SUS), e com a criação, no Centro de Saúde I, de uma equipe mínima de Saúde M ental (um psicólogo e um médico-clínico), a qual realizava apenas psicodiagnóstico, medicação e internação psiquiátrica. Após 1995, a equipefoi ampliada para dois psicólogos, um assistente social e um médico psiquiatra e começou a desenvolver ações com o objetivo de implantar ações assistenciais substitutivas à internação psiquiátrica.

Em Assis, a assistência pública em Saúde M ental acompanha, à distância, as políticas nacional eestadual para o setor, em especial aquelas construídas após 1964. Assim, em 1971, o Lions Club, estimulado pelo crescimento da rede de hospitais particulares e conveniados com o poder público, decidiu construir um macro hospital psiquiátrico na cidade, com 5 mil metros quadrados de área construída. No final daquele ano, a obra foi paralisada por falta de recursos financeiros e o prédio ficou abandonado, exposto à deterioração e à depredaçãa ${ }^{11}$.

No início da década de 1980, iniciou-se, na Faculdade de Ciências e Letras de Assis - Unesp, a discussão sobre a assistência em Saúde M ental na cidade, motivada pela intenção do Lions Clube de doar 0 prédio inacabado do hospital psiquiátrico. Nesse contexto, foi elaborado, por uma comissão formada por representantes do Lions, da universidade e das entidades de profissionais da área, um projeto de Ambulatório de Saúde M ental para funcionar em uma parte daquele prédio. Tal projeto era inspirado no modelo da psiquiatria comunitária americana e, em especial, na experiência realizada no Estado de São Paulo por Luiz Cerqueira na década de 1970.

O Ambulatório de Saúde M ental foi inaugurado em 1984, com a administração de uma outra comissão, nomeada pela entidadefilantrópica, sendo que suas atividades centravam-se na consulta psiquiátrica ena psicoterapia individual.
A partir de 1984, outros movimentos empenharam-se em construir um Projeto de Saúde M ental público para o município e a região que contemplassea criação deum ambulatório deSaúde M ental integrado num sistema hierarquizado. Dentre eles, destacou-se a criação do núcleo de estágio curricular do Curso de Psicologia da Faculdade de Ciências e Letras de Assis-Unesp, junto ao Centro de Saúde I.

Ao final de 1987, a Prefeitura Municipal, sem nenhuma discussão prévia com os segmentos envolvidos com a Saúde M ental, encampou o ambulatório do hospital psiquiátrico, sendo que o atendimento em Saúde M ental do Centro de Saúde I deslocou-se para o ambulatório de Saúde M ental, com a transferência desordenada dos usuários.

A partir daquele momento, a atenção em Saúde M ental em Assi s sofreu um refluxo e, apenasna gestão municipal de 1993-96, quando houve um efetivo esforço de seconsolidar o Sistemaú nico de Saúde, a assistência em Saúde M ental passou a integrar o sistema.

\section{Consolidação do SUS \\ eas ressonâncias da reforma psiquiátrica}

\section{Campo teórico-conceitual}

$N$ as entrevistas analisadas, foram constatadas, basicamente, duas concepções de sofrimento mental. U ma primeira, ainda predominante e em consonância com o modelo manicomial, pode ser observada neste depoimento: Por incrível que pareça, tem profissionais da equipe que priorizam a internação ainda. M esmo os psicólogos priorizam a internação. (G2-Assis).

Nesta perspectiva, os objetivos do tratamento estavam centrados na remissão dos sintomas e na diminuição da internação, sendo a medicação, a terapêutica central do tratamento eas outras ações apenas complementares: Quando o paciente está em crise, ele não está bem, o primeiro passo é medicar, esperar eliminar o sintoma da crise e só então propor as atividades. (G2-Cândido M ota).

Portanto, o trabalho da equipe seria ainda médico-centrado, apesar do compromisso de propiciar um tratamento mais humano e digno ao usuário e produzir a ressocial ização: Trabalho insistentemente pela ressocialização do paciente. (T4-Cândido M ota).

$\mathrm{N}$ a segunda concepção, o sofrimento psíquico foi compreendido como fenômeno histórico-social e peculiar: Eu acho que ela é uma doença social, cultural e não é só física e emocional. (G3-Assis). 
Associada a essa visão, alguns trabalhadores explicitavam a importância de se entrar com contato com o sofrimento psíquico do sujeito: Eu já venho estudando alguns autores que se propõem a pensar de uma outra maneira. E isso diferencia a escuta da subjetividade do usuário. Você imaginar que ele é alguém que pode conviver melhor, com menos sofrimento. (G2-Cândido M ota).

Os profissionais apontaram, como finalidade do tratamento, a promoção de uma reinserção social capaz de garantir o direito ao trabal ho, à cidadania e ao reposicionamento singular do usuário na sociedade: Criar uma nova singularidade, deuma nova subjetividade social, isso ainda não.(G2-Cândido Mota).

Seguramente, esta última era uma concepção que revelava uma abertura para uma abordagem mais abrangente e conseqüente para o sofrimento psíquico humano.

\section{Campo técnico-assistencial}

N esse campo, constatou-se uma mudança mais ampla. A política nacional de Saúde M ental, assumida pelo Ministério da Saúde principalmente a partir de 2000, tem contribuído para essa mudança, na medida em que os gestores municipais passaram a ter acesso a uma legislação comprometida com a atenção psi cossocial e a vários incentivos financeiros para implantá-la e implementá-la.

Os municípios estudados procuraram transformar as propostas da reforma psiquiátrica em atos, mesmo que de maneira lenta, gradativa e à custa de esforços da equipe, pelo menos no que se referia à diminuição da internação psiquiátrica.

Em Cândido M ota, a equipe, responsável por toda a demanda da cidade em Saúde M ental, era composta de um coordenador (psicólogo), um psiquiatra, cinco psicólogos, uma técnica deenfermagem e uma assistente social.

Em Assis, era mais evidente a organização da atenção na saúde e na Saúde M ental em uma rede regionalizada e hierarquizada em níveis primário, secundário eterciário. Os serviçosfuncionavam em vários locais e eram articulados em um sistema de referência e contra-referência. No setor de Saúde M ental, havia um psicólogo em sete Unidades de Saúde (UBS) com a atribuição de atuar nos seguintes setores: Seria um investindo em prevenção, em orientação, até em psicoterapia. Poderíamos ampliar as ações junto à comunidade, dentro das escolas, ou em instituições que estão ao redor. (G3-Assis).

0 ambulatório era responsável pelos atendimentos em terapêutica medicamentosa e em psicoterapia individual e grupal, encaminhados pelas
UBS. O CAPS II, que se caracterizava como um serviço intermediário entre o ambulatório eo hospital psiquiátrico, atendia os usuários com sofrimento mental grave. Essa forma de organização dos serviços produzia problemas no sistema de referência e contra-referência e, conseqüentemente, havia muitas reclamações de usuários, profissionais e gestores.

Em Assis, em 1997, a SM S elaborou um projeto de NAPS/CAPS com vistas a estabelecer convênio com o M inistério da Saúde, mas ele não foi cadastrado naquele momento, apenas em 2002. M esmo assim, o município implantou, naquele ano, o Projeto de Atenção Intensiva (PAI), cujas atividades eram desenvolvidas no ambulatório deSaúdeM ental: Quando eu entrei aqui não existia o CAPS. M ontamos o grupo de música e eu montei o da escolinha. $M$ ais tarde vieram os estagiários da U nesp para ajudar. (T2-Assis). E a criação do CAPS ampliou as ações intensivas e de inserção social iniciados pelo PAI, conforme será abordado posteriormente.

Enfim, os dois municípios ainda reproduziam, nos seus serviços de Saúde M ental, as propostas contidas no documento da Secretaria Estadual sobre o trabalho para equipes em UBS, em Ambulatório deSaúdeM ental ${ }^{12}$. N essa perspectiva, o CAPS continha um serviço intermediário, 0 ambulatório e o hospital psiquiátrico, e não substitutivo.

Nenhum dos municípios estudados possuía, em funcionamento, serviços de urgência e emergência. Em Cândido M ota, o psiquiatra era responsável pe las intercorrências psiquiátricas. Às vezes, na sua ausência, al gum médico da unidade de saúde atendia determinada situação e fazia o encaminhamento, geralmente para internação psiquiátrica. Outra possibilidadeparaurgênciaeemergênciaem SaúdeM ental era o PS da Santa Casa, a partir das $18 \mathrm{hs}$. Por isso, 0 Programa de Saúde M ental fazia al gumas tentativas para que o PS acolhesse as urgências da Saúde M ental: A gente tem buscado um contato mais freqüente junto à Santa Casa, que é a nossa única referência de emergência. Hoje, a gente tem um contato com um novo enfermeiro. É um enfermeiro queestá lá há, mais ou menos, seis meses. (G2-Cândido M ota).

Em Assis, o CAPS e o ambulatório não tinham a atribuição de acolher as situações deemergência, incumbindo-se apenas de al gumas intercorrências de seus usuários. As situações de urgência e emergência da Saúde M ental eram encaminhadas para internação nos hospitais de referência ou atendidas no PS municipal. Fiel à lógica do próprio modelo de sistema integrado e hierarquizado, às vezes, o PS resistia ou reclamava de receber muitas das situações da demanda espontânea da assistência, notadamente no horário diurno. 
A PM constituía um recurso muito utilizado no atendimento das situações de urgência e emergência em SaúdeM ental do município deAssis. Os policiais já compunham o cenário da assistência em Saúde M ental local, uma vez que sempre eram acionados pelos familiares ou mesmo pelos serviços de atenção primária e secundária: É por isso que, quando se tem um paciente agitado, a gente chama a polícia militar pra levar no PS. (G4-Assis).

Os atendimentos realizados no PS recebiam muitas reclamações, princi palmente pela ausência de retaguarda da equipe de psiquiatria do Hospital Regional para o PS, a exemplo do que ocorria no caso de outras especialidades médicas: Deveria existir no hospital geral eno PS um profissional pre parado para essa situação. (U 3-Assis).

Os profissionais dos serviços de Saúde M ental dos dois municípios consideravam que o trabalho em equipe era importante para se construir as ações e organizar os serviços comprometidos com a atenção psicossocial. As equipes contavam com a participação de estagiários de psicologia da UNESP e de profissionais recém-formados do ProgramadeAprimoramento Profissional (equivalente à especialização), em Saúde M ental e Saúde Pública da DIR VIII, vinculado ao Programa de Bolsas para M édicose Outros Profissionais deN ível Superior queatuam na Área da Saúde, criado pelo Governo do Estado de São Paulo e gerido pela Fundação de Desenvolvimento Administrativo (FUNDAP), cujo objetivo era a formação e 0 aprimoramento de recursos humanos para a área da Saúde M ental em consonância com o modelo de atenção psicossocial.

No entanto, havia diferenças na maneira de cada equipe perceber a presença desses atores sociais. Em Cândido M ota, os aprimorandos e os estagiários definiam suas atividades no serviço a partir de seus interesses pessoais e dos objetivos acadêmicos, articuladas que eram com a demanda do serviço. De maneira geral, a equipe não tinha problemas de integração com esses "atores estrangeiros e de passagem": Eu acho que tem uma aceitação interessante, pois há uma expectativa em relação ao aprimorando. Há esse vínculo com a universidade e eles resgatam isso em vários momentos. (T3-Cândido M ota)

Em Assis, a situação se apresentou diferente. $H$ avia mais divergências e constantes conflitos entre a equipe e os estagiários. No início do PAI, as oficinas eram realizadas em conjunto pelos profissionais e, principalmente, os estagiários: Com essa mudança de coordenação, a equipeseafastou da pior maneira. E eu já falei, que para ela ver essa equipe envolvida do jeito que era antes, ela vai ter que pedir mesmo, porque ninguém mais vai voltar espontaneamente. (T3-Assis).
M as, de maneira geral, as atividades do estágio curricular e do curso deaprimoramento desenvolvidas nesses municípios revelam uma rica e rel evante experiência deinserção da universidadena comunidade local e regional. Tais atividades acadêmicoassistenciais contribuem para uma maior aproximação entre as diferentes esferas da sociedade, tanto no âmbito da universidade como fora dela, e fortalecem a articulação entre o saber transmitido na universidade e a construção de novos saberes, bem como a formação dealunos críticos e preparados para intervir nas diferentes realidades que encontrarem no seu exercício profissional futuro. Esta parceria entre a universidade e as instituições de saúde também contribui para implantação das políticas públicas para Saúde M ental consoantes com a atenção psicossocial eo SU S e, conseqüentemente, para a mel horia da qualidade da atenção prestada aos usuários pelos serviços de saúde municipais.

Nos dois municípios, as equipes organizavam o trabal ho por intermédio de reuniões. Em Cândido M ota, elas eram semanais, com a participação mensal dos estagiários e do supervisor de estágio. A equipe de apoio participava apenas em situações pontuais e esporádicas e os usuários não tinham nenhuma participação.

Em Assis, no ambulatório de Saúde Mental e no CAPS, havia duas reuniões semanais: uma com os estagiários ea equipetécnica, menos os médicos; outra com a equipetécnica, incluindo os médicose a equipe de apoio. Também era real izada uma reunião mensal com a participação dos psicólogos das UBS, da coordenação do ambulatório/CAPS e da coordenação deSaúdeM ental do município: A gente tenta discutir em cima dos casos concretos, dos encaminhamentos e dos problemas trazidos. (G3-Assis).

As dificuldades e as divergências identificadas nas reuniões foram ressaltadas como obstáculos para $o$ desenvolvimento da equipe e 0 andamento do trabalho: Eu acho que a equipe tem um medo de se responsabilizar pelas novas, por novas coisas. (T3Cândido M ota).

Enfim, era constante a percepção de que, nas reuniões de equipe, a discussão dos problemas de algum usuário e de seu cuidado era uma maneira dequestionar ecriticar indiretamente a conduta de algum membro da equipe. Tais momentos produziam ruídos cuja repercussão se estendia para fora da reunião e chegavam à sala da equipe, como se fossem problemas apenas pessoais: Se as diferenças teóricas e práticas começam a ser vivenciadas como pessoais, transformam-se num ataque à pessoa. (G2-Cândido M ota).

Parecequequando vocêavalia quealgum paciente não tem condições pra participar de uma deter- 
minada oficina, tudo vira discussão, tudo vira briga e acaba virando uma coisa pessoal. (T3-Assis).

De maneira geral, os conflitos das equipes dos dois municípios apareciam localizados no âmbito das relações pessoais-afetivas e, freqüentemente, deslocavam-se para a reivindicação de supervisão de novas técnicas de tratamento, isto é, de especializações: Eu penso que eu preciso me aperfeiçoar no atendimento familiar para que eu possa trabalhar e orientar as famílias. (T2-Cândido Mota).

Os profissionais das equipes, seja em Assis, seja em Cândido Mota, funcionavam como uma mera junção de pessoas, segundo a lógica de "linha de montagem", centrada no modelo taylorista. Nesse sentido, os profissionais pareciam ter dificuldades de problematizar seu modo de atuar como produto da alienação produzida pela própria divisão do processo de trabalho, de modo que as equipes dos serviços de Saúde M ental pudessem construir o fazer coletivo e a descoberta de novas entradas para recompor o seu projeto deatenção psicossocial, embora os conflitos apareçam como divergências pessoai $s^{7,8,13}$.

0 processo de elaboração do projeto de trabaIho da equipe exigequeesta desenvolva inicialmente o seu reconhecimento como grupo. Depois, é necessário conhecer os seus recursos técnico-políticos, analisar os saberes em disputa e compor um referencial para agir. Finalmente, o grupo identifica os recursos (saberes, poder, legitimidade, tempo, ousadia, paixão, entre outros) que possui para realizar seu projeto ${ }^{14}$.

Enfim, as análises sobre o funcionamento da equipe, suas dificuldades e seus conflitos parecem apontar para uma crise da coordenação nos serviços dos dois municípios. As equipes e as coordenações dos serviços, embora reconhecessem essa situação, não conseguiam construir, nos serviços, um espaço coletivo, com uma maior horizontalização nas relações intra-institucionais capazes de propiciar a responsabilização real do serviço pelo cuidado do usuário, de modo a considerá-lo em sua singularidade.

As ações de Saúde M ental desenvolvidas nos dois municípios eram predominantemente as já consagradas no campo, tais como: recepção, consulta psiquiátrica e medicação, psi coterapia grupal e individual; porém, a consulta psiquiátrica e a medicação constituíam os eixos centrais dos serviços: N ós buscamosaumentar o número de horas [do psiquiatra] para que se pudesse dar um respaldo às psicólogas, às assistentes sociais que trabalham no serviço. (G1-Cândido M ota).

A utilização da medicação em grande escala reafirmaria a idéia de queo objetivo central do tratamento é a supressão dos sintomas do usuário e 0 restabelecimento de um suposto equilíbrio mental: Eletem que tomar remédio durantea vida inteira. E tomar remédio faz muito bem a ele. E ele está comportado, mas a doutora achou que ele está meio confuso ao conversar (U2-Assis).

Uma outra forma de intervenção realizada nos serviços dos municípios era a oficina terapêutica. No entanto, a inserção das oficinas nos serviços e sua articulação com as demais ações de cuidado eram diferentes. Em Cândido M ota, em 1998, foi contratada uma psicóloga para desenvolver oficinas terapêuticas com os usuários adultos no ambulatório deSaúde M ental. Tal experiência foi considerada importante para os usuários: $\mathrm{Na}$ oficina eu gosto de estar com os meus colegas. Eu participo, eu sorrio, eu converso, eu canto, eu brinco, conto piada, conto verso e eu me sinto muito bem indo lá: aquela é a minha família. (U1-Cândido M ota).

M esmo assim, a equipe teve dificuldades para integrar essa atividade no seu cotidiano: Eu percebo que ainda não se tem muita clareza o para quê dessa oficina como dispositivo, além de atendimento em grupo e individual. (T3-Cândido M ota).

No município deAssis, as oficinas terapêuticas estavam mais consolidadas, mas eram coordenadas por estagiários de psicologia e tinham como objetivo propiciar ao usuário o exercício de sua singularidade e de cidadania: $E$ a oficina entra neste espaço com a perspectiva ética de criação de mundos, onde o desejo se coloca como os pés que a vida tem para caminhar, melhorando assim a qualidade de vida e exercendo a cidadania ${ }^{15}$. E a intervenção nas famílias dos usuários também foi sublinhada como muito importantenos dois municípios: U ma das críticas mais comuns é dos familiares, porque deve haver um trabalho intensivo com eles que a gente ainda não tem feito. (G3- Assis) .

Porém, as equipes dos municípios realizavam tais ações ainda de modo pontual, esporádico e, muitas vezes, relacionado à administração da medicação: Trabalho familiar. E se for necessário, também ajudar no manuseio da medicação. Em uns a gente consegue fazer, mas não em todos. (G2-Cândido Mota).

Em 2002, foi criada, no município de Assis, a Associação de Usuários, Familiares, Trabalhadores e Amigos da Saúde M ental - PIRASSIS - a partir da iniciativa dos estagiários do curso de psicologia da UNESP: Era uma coisa antiga a idéia de fazer a associação. Os estagiários colocavam nas nossas cabeças que tinham que montar uma associação ou talvez uma cooperativa, pois faltava muito material para as oficinas. (U 1-Assis). M as a referida associação ainda precisava constituir-se de fato num espaço de mediação entre os usuários, suas famí- 
lias e a sociedade. Ou seja, em 2002, ainda eram pontuais e pouco numerosas as ações nos espaços públicos das cidades e, portanto, não contribuíam para a construção de uma rede de dispositivos articulada em propostas comuns e coletivas, produtora de cidadania e de transformação social.

Foi possível observar que a tentativa dos municípios de construir uma "rede de serviços" ou "rede de assistência" de Saúde M ental, hierarquizada e em um sistema de referência-contra-referência, tem impedido a responsabilização do serviço pelas ações de Saúde M ental em uma determinada área e a articulação das ações de cuidado re alizadas pelos diversos dispositivos: pronto-socorros, hospitais gerais e psiquiátricos, escolas, conselhos tutelares, promotoria pública, creches, associações de bairro, entidades filantrópicas. Em conseqüência disso, os diversos serviços nos diferentes níveis de atenção não reconhecem a existência de várias lógicas de funcionamento, de múltiplos atravessamentos provocados por diversos fluxos dos usuários.

As ações no território devem ativar os recursos do habitat de origem ou de referência do usuário, necessários para a construção de projetos terapêuticos emancipadores e transformadores do imaginário social. Nessa perspectiva, o termo "território" aqui adotado não se refere apenas ao espaço geográfico, mas também aos espaços demográfico, epidemiológico, tecnológico, econômico, social, cultural, político, produto de um processo permanente em que se articulam diferentes sujeitos políticos com suas necessidades, interesses, desejos e sonhos ${ }^{16,17}$.

A responsabilização pelo tratamento do usuário presume a invenção, o planejamento, a avaliação e a gestão dos novos saberes e fazeres no coletivo, garantindo a participação de todos os atores envolvidos. Essa produção coletiva não é natural: elaéconstruída no cotidiano do serviço. A equipe, a coordenação e a clientela precisam desenvolver sua capacidade de análise da realidade de seu trabalho e de seu "entorno" para construir seu projeto, conhecer e problematizar seus referenciais teórico-técnico-políticos, criar mediações, equacionar seus conflitos, reorganizar o trabalho.

Em síntese, uma efetiva consolidação das propostas atuais da reforma psiquiátrica requer, entre outras ações, um maior compromisso dos gestores com a atenção em Saúde M ental, um maior investimento no suporte para as equipes de Saúde M ental das UBS, CAPS e a articulação com o Programa Saúde da Família-PSF. Também deve estimular a organização e a participação dos usuários e familiares, bem como a integralidade e a interse- torialidade das ações desenvolvidas nas cidades para construir uma rede de cuidado einclusão social.

\section{Campo político-jurídico}

Os vários segmentos sociais dos municípios conheciam os princípios e propostas da reforma psiquiátrica, embora esse conhecimento apresentasse diferenças entre os gestores, trabalhadores e usuários. Os gestores, naturalmente, e até por necessidade do seu cargo, demonstraram ter maiores informações sobre a legislação (portarias, normas e projetos do M S e SES-SP): Existia uma luta antimanicomial que eu acho queveio bem antes dessa política. Então, para mim, já está mais claro que a gente precisava ter um outro tipo de trabalho. (G1Assis). Os trabalhadores pareciam desconhecer a legislação: Eles dizem que nunca receberam uma portaria. A gentemanda, mas eles não sabem ou não se lembram.(G2 de Assis). Ou evidenciaram pouco envolvimento com o tema: M as eu tenho sentido um pouco de dificuldade dos gestores também estarem entendendo e implementando isso, e dos profissionais para promover outras práticas e repensar essa orientação. (T3-Cândido M ota). Os usuários evidenciaram interesse na política de distribuição de medicamentos, de ben efícios sociais como, por exemplo, da Lei Orgânica da Assistência Social (LOAS): A família passou a entender a necessidade da medicação. E que uma internação faz mal para 0 paciente. 0 benefício [LOAS] ajudou esse pacientea ser respeitado, porque ele participa de orçamento da casa. (T2-Assis).

Os municípios, pressionados pela política econômica, buscam novos recursos financeiros para poder governar, sendo que qualquer possibilidade de captar recursos é sempre bem-vinda. Entretanto, os investimentos propostos pelo M inistério da Saúde para a Saúde M ental nem sempre foram considerados boas fontes de captação de recursos. As críticas referiam-se à necessi dade da contrapartida do município, à existência de verbas vinculadas a projetos. Tal situação, acrescida das exigências da Lei de ResponsabilidadeFiscal, principalmente no tocante às limitações com despesas com recursos humanos, apareceram como justificativas do pouco interesse dos municípios pelos recursos disponibilizados pelo M inistério da Saúde para a Saúde M ental: Quando o M inistério da Saúde divulga e incentiva a criação do CAPS nos municípios, há semprea promessa dequeos recursos para esse serviço vão aumentar. M as isso é muito perigo, pois a contrapartida municipal é maior. (G1-Assis)

A alternância de poder na esfera do executivo municipal foi apontada como um outro obstácu- 
lo no processo de construção da atenção psicossocial, pois os serviços se organizavam de maneira precária e frágil, o que os tornava vulneráveis no início de cada nova gestão administrativa: Então, 0 problema é, o que você tinha numa certa administração, a outra não vai usar, porquenão foi ela quem criou. Semprehá mudanças de equipe, eisso émuito ruim. (G1-Assis)

São inquestionáveis os benefícios resultantes da gestão local da atenção em saúde para a população, a partir da implementação do SU S, após 1989. Naquele momento, eram grandes as expectativas decorrentes da promulgação da Constituição de 1988, principalmenteno que se referia à ampliação do papel do município como composição federativa. As perspectivas de maior autonomia, de novas responsabilidades e de mais recursos para os municípios, aliadas à esperança de mudança no panorama político do país (a proximidade da primeira eleição direta para Presidente da República, desde 1960) e a ampliação e a consolidação dos movimentos sociais contribuíram para a eficácia demuitas administrações municipais na gestão das políticas públicas.

Tal cenário continha a promessa de renovação da vida política. E apontava para um novo momento político em queo Estado é concebido como arena de lutas políticas, com uma nova correlação de forças entre as classes dominantes e as classes dominadas, havendo, portanto, o fortalecimento da autonomia da sociedade civil.

Essecontexto político não se manteve na década de 1990. A redução do papel do Estado na gestão das políticas públicas tem impedido a sustentação do pacto social construído pela sociedade civil. Nesse processo, as regras do mercado são consideradas suficientes para produzir o bem-estar do homem, podendo ser complementadas com al gumas ações políticas compensatórias. Do Estado espera-se que seja capaz, de um lado, de propiciar a mobilidade externa do capital, do consumo e do sistema financeiro e, de outro, de controlar o poder dos movimentos sociais.

N esse sentido, a descentralização da gestão das políticas públicas continua se consolidando, mas não necessariamente comprometida com a qualidade de vida da população. 0 objetivo da gestão desloca-se para o controle e o equilíbrio do déficit público. Assim, a maioria dos municípios estaria gerenciando a pulverização das políticas públicas e a precarização dos direitos constitucionais da população. 0 desafio nessa primeira década do século XXI éde fazer avançar o SUS ea construção da rede deatenção psicossocial e, essencialmente, criar uma rede de resistência para a manutenção de seus pressupostos básicos.

$M$ as se, de um lado, os municípios têm encontrado dificuldades para cumprir as suas atribuições, de outro, os gestores municipaisnem sempre estão compromissados suficientemente com a política nacional de saúde, de modo a implantar as propostas do M inistério da Saúde para consolidar - SUS, e mesmo para solicitar recursos disponíveis. Enfim, Não há nenhuma garantia intrínseca à autonomia dos governos locais que os torne responsáveis, comprometidos com as necessidades dos cidadãos e determinados a administrar com eficiência ${ }^{18}$.

Nos municípios estudados, a atenção em Saúde Mental não é prioridade para os gestores: Eu não vejo a SM como uma prioridade para o gestor. Eu vejo que ele está satisfeito do jeito que ela está funcionando. M as uma prioridade de olhar para 0 setor. (G2-Cândido M ota)

Também existea falta demaior empenho ecomprometimento com as propostas do SUS e da reforma psiquiátrica, no tocante à necessidade de mudança do modelo assistencial: Temos caminhado muito lentamente. Fica muito distante o que é proposto do que é realizado. (G2-Cândido M ota)

É necessário que haja mecanismos mais efetivos de orientação para a mudança do modelo assistencial e de acompanhamento da aplicação dos recursos financeiros, não somenteem nível local, mas estadual efederal. Para isso, faz-senecessária a retomada das ações realizadas pelos diversos segmentos sociais e, dentre eles, os conselhos profissionais comprometidos com essa mudança. As comissões de reforma psiquiátrica (nacional e estaduais) e os movimentos sociais (o da Luta Antimanicomial) devem retomar e ampliar as ações de acompanhamento, orientação efiscalização da implantação das diretrizesepropostas deações eserviços nos municípios, em especial, os de pequeno e médio portes, além decontribuírem para o fortalecimento da participação popular e do controle social.

É importante ainda destacar quenão existenenhuma legislação municipal que contemple a mudança do modelo assistencial nos municípios estudados. Há apenas algumas diretrizes contidas em conferências de saúde e na I Conferência Regional de Saúde, já analisadas anteriormente. As conferências de saúde dessas cidades vêm sendo espaços importantes de participação popular e para deliberações, visando à construção de uma política local para os vários setores da saúde. No entanto, elas ainda não conseguem desempenhar seu papel de co-participante de fato no processo de construção da política local de saúde e da atenção psicossocial. 


\section{Campo sociocultural}

Os municípios pouco desenvolviam ações para transformarem a percepção da população acerca da doença mental edas pessoas consideradas como tal. Em geral, os serviços dos dois municípios avaliaram queo estigma social para com a pessoa considerada "doente mental" ainda era muito grande: A própria família criou um estigma dessas pessoas. Eles tentam até dizer que não tem ninguém com esse problema na família, mas não é bem assim. Hoje, caiu o conceito de louco, agitado e eles são tratados como psicóticos, neuróticos. (G1-Cândido M ota)

No entanto, na medida em que aumentavam as ações desenvolvidas nos espaços públicos da cidade, com a população passando a interagir mais com os usuários da rede de Saúde M ental, observou-se uma maior aceitação ou uma maior tolerância e condescendência para com tais pacientes, notadamente quando eles não estavam em crise: Eu ouvi relatos na Conferência M unicipal deSaúde. As pessoas acharam incrível a participação de alguns usuários da Saúde M ental contribuindo para o processo. (U3-Assis)

Finalizando, é possível perceber quea realização deações no território do serviço enos espaços públicos pode permitir uma maior compreensão da sociedade sobre o sofrimento psíquico e, conseqüentemente, uma maior tolerância eaceitação do usuário para com os serviços de Saúde M ental (na realidade, essa mudança de percepção deveria ser tema de outra investigação, por sinal muito interessante).

Os municípios estudados realizavam também poucas ações intersetoriais, mesmo entre os diversos setores da administração pública, embora em seus documentos destacassem sua importância. Entre as justificativas, era recorrente 0 preconceito para com o usuário da Saúde M ental: A gente é muito excluída ainda. Fica parecendo que a SM não tem nada a ver com as pessoas ecom o resto das coisas (G3-Assis); a falta de projetos de inclusão social: É difícil porque a Secretaria da Assi stência não tem projeto nenhum. $E$ deEducação também não (G2-Cândido M ota); e os entraves burocráticos das secretarias de governos: Porque a gente a recebe [alimentação] de uma parceria com a Secre taria da Educação que tem a cozinha-piloto. Quando a Educação entra em férias, não tem comida, não tem refeição para os pacientes. (G4-Assis).

0 município maior tem mais recursos para desenvolver ações intersetoriais, em especial com a Secretaria de Assistência Social: Teve um avanço nessa parceria, no sentido de conseguir encaixar sete usuários em atividades lá (monitores de projetos como oficina de pintura e horta). (G3-Assis)
Contudo, essa situação não garante a construção de uma rede de dispositivos articulada em propostas comuns e coletivas; enfim, de uma rede produtora de transformação social e cidadania. Para constituir uma rede de resistência edisparadora de mudanças, deve haver nos municípios um maior estímulo para a organização e para a participação dos usuários e familiares, a integralidade dos dispositivos de saúde, de assistência social e de cultura neles existentes, com o objetivo de construir uma rede decuidado ereinserção social emancipadora. Também é indispensável construir uma interlocução com o Poder Judiciário para propiciar a mudança na cultura jurídica das concepções acerca da doença mental e das formas de tratamentos que envolvem a exclusão, a segregação e 0 confinamento dos usuários da Saúde M ental e, conseqüentemente, a compreensão e a aceitação dosnovos serviços de atenção psicossocial, inclusive para os dependentes químicos e outras drogas.

No que se refere à relação da população e dos serviços de Saúde M ental, observou-se que, nos dois municípios, os gestores e trabalhadores avaliaram que a população mantinha uma boa

relação com os serviços de Saúde M ental: N osso serviço é, para a nossa al egria, visto de uma forma muito boa. Basta ver o número de pessoas que são atendidas e se dirigem para cá, por ouvir falar bem do serviço. (G1-Cândido M ota)

$M$ as não tenho reclamação sobre a Saúde M ental. Eu acho que o pessoal que está trabalhando com SaúdeM ental édiferenciado. 0 pessoal quetrabalha no CAPS é comprometido e se dedicam. ( G1-Assis).

Também, entre os usuários, encontrou-se uma visão positiva do serviço: 0 programa [SM] tem dado resultado para os usuários, porque, eu acho que eles estão sendo bem assistidos. (U 3-Cândido M ota)

No município de Assis, ocorreram mais reclamações. Estas se centravam nos atrasos dos médicos: $E$, às vezes, o médico chega aqui com duas horas e meia de atraso. Então, os pacientes ficam agitados. (T1-Assis); ena falta de medicação: Vocêrecebeuma reclamação dequefal tou um medicamento ou queele chegou atrasado; mas a genteprocura não deixar faltar. (G1-Assis)

Também foi identificada uma outra reclamação relacionada à não aceitação inicial dos familiares da proposta de tratamento substitutiva à internação psiquiátrica. Porém, a própria equipe admite a falta de trabalho mais efetivo com os familiares, com o objetivo de produzir demanda para um outro tipo de tratamento: U ma das críticas mais comuns édosfamiliares. Eles esperam poder deixar o usuário lá, para que eles possam ir trabalhar. Às vezes, quando a família briga porque ela quer internar o usuário. (G3-Assis) 
Em relação aos mecanismos de participação e controle social, constatou-se que no município menor, estes ainda não são efetivos: Quando foram montados esses conselhos procurava obedecer às leis. Então os prefeitos fizeram uma loucura, pegaram 0 pessoal a laço. Eu acho que cinqüenta por cento deles, hoje, desconhecem os programase os projetos dentro da área de Saúde. (U3-Cândido M ota)

No município de médio porte, as instâncias de participação popular econtrolesocial estavam mais consolidadas, principalmente quando comparadas às existentes nos demais municípios da região. Entretanto, a atuação do CM S e a participação ativa de seus conselheiros não podem ser consideradas como indicadores da existência de mobilização e organização da sociedade civil em torno das questões da saúde: É um Conselho ativo, atuante. $M$ as precisa-se urgentemente de um treinamento para consel hei ro. 0 conselheiro é leigo e el enão sabe no que ele está votando. (G2-Assis)

Porém, a atenção em Saúde M ental não parece ter espaço no CM S de saúde. As discussões acerca desse tema e do serviço são apenas pontuais e esporádicas: Só aparece quando eu levo. Então eu uso esse espaço para informar, pois não tem muita solicitação sobre como funciona a Saúde M ental. N em recebe-se queixa! (G2-Cândido M ota)

Essas dificuldades se reproduzem também na organização e no funcionamento dos Conselhos Gestores existentes nas unidades desaúde: A população não sabe direito o queéaquilo eas pessoas que às vezes têm mais recursos não querem participar. (G3-Assis)

Em síntese, a existência de pou cos espaços políticos de negociação entre os diversos atores sociais interfere na produção de conhecimento coletivo acerca do sofrimento psíquico e na diminuição do estigma social da loucura.

Deve-se ressaltar, ainda, que a implantação e a consolidação das diretrizes e das propostas da reforma psiquiátrica supõem uma construção coletiva que exige envolvimento dos atores dos diversos segmentos da sociedade. 0 empenho e a organização dos trabalhadores, dos usuários, dos familiares e das demais entidades da sociedade civil são fundamentais. M as, sem dúvida al guma, é imprescindível que os governos municipais rompam com um modelo de administração pública centrado na conservação e nas pequenas interven ções no espaço urbano, na construção de grandes obras, no fisiologismo político, assumindo um projeto de governo autônomo, centrado em políticas sociais e voltado para a melhoria de vida de toda a população.

\section{Consideraçõesfinais}

Este estudo pretendeu trazer subsídios importantes para a construção de uma rede articulada de atenção psicossocial nos municípios de pequeno e médio portes, mas também procurou mostrar obstáculos significativos de efetivar as diretrizes e as propostas da reforma psiquiátrica, atualmente contidas na política nacional de Saúde M ental.

As diretrizes e as propostas da reforma psiquiátrica têm conseguido adentrar no Sistema Ú nico de Saúde dos diversos municípios, principalmente quando os segmentos (gestores, trabalhadores e usuários) envolvidos na atenção em Saúde M ental estão comprometidos com as mudanças. Contudo, é necessário, de fato, que haja também o comprometimento dos gestores municipais com a população e com a melhoria de suas condições de vida para a criação de serviços substitutivos em Saúde M ental.

O outro aspecto a ser ressaltado são os riscos da medicalização da demanda da Saúde M ental, quando se tem como objetivo e formas de tratamento apenas a diminuição da internação psiquiátrica, sem qualquer investimento na formação permanentedas equipes dos serviços, comprometida com os pressupostos teóricos da atenção psicossocial.

Também constituiria obstáculo para a reforma psiquiátrica a hipótese de os serviços, ao retomarem e estimularem as práticas identificadas com tratamento moral, não conseguirem produzir novas práticas para propiciar ao usuário 0 acesso a bens, à cultura, à educação, ao trabalho, à convivência, à história, enfim, ao direito de ser sujeito e cidadão.

$\mathrm{N}$ a perspectiva do tratamento moral, o acolhimento e o cuidado do usuário estaria centrado apenas na tolerância e no suprimento solicitado pelo usuário. As metas da solidariedade e da diminuição das desigualdades sociais, necessárias para que a pessoa considerada doente mental passe a ter direitos e autonomia, seriam substituídas pelo voluntarismo e pela compaixão.

Assim, os serviços e as equipes funcionariam por impulso, seguindo o princípio do "quanto antes melhor", desvinculado, porém, de qual quer preocupação com as conseqüências que a ação poderia provocar no usuário. Os serviços poderiam ou deveriam ofertar algo que suprimisse o pedido do usuário, antes mesmo de acolhê-lo eouvi-lo. Nessa perspectiva, a compaixão piedosa estaria sen do retomada como categoria de controle social, capaz de contribuir para o estabelecimento de uma ordem social mais justa, porém desvinculada de qualquer transformação das condições materiais geradoras de desigualdades. 
Em síntese, o processo de desinstitucionalização e a superação do modelo manicomial exigem transformações da sociedade para se construir uma história que privilegie a vida, portanto, inserindose no campo das lutas sociais. Porém, é possível construir utopias no próprio cotidiano para viabilizar a transição paradigmática exigida pelas diretrizes e propostas da reforma psiquiátrica, que estariam centradas no investimento nos trabalhadores daSaúdeM ental, principalmenteno queserefere à formação permanente dos profissionais dos serviços e na reformulação da formação profissional. Tais utopias deveriam também estar voltadas para os usuários e a população, para viabilizar sua organização e sua participação nesse processo.

\section{Colaboradores}

CA Luzio foi autora da pesquisa original, participou detodas as etapas da elaboração do artigo; L'Abbate orientou o estudo original eparticipou igual mente de todas as etapas da elaboração do artigo.

\section{Referências}

1. Luzio CA, L'Abbate S. A reforma psiquiátrica brasileira: aspectos históricos e técnico-assistenciais das experiências de São Paulo, Santos e Campinas. Interface (Botucatu) 2006; 10(20): 281-298.

2. Instituto Brasileiro de Geografia e Estatística. Censo demográfico 2000. Resultados do universo. 2000. [acessado 2002 dez 15]. Disponível em: http://www. ibge.gov.br/home/estatistica/populacao/censo2000/ ufs. php?tipo $=31$

3. Luzio CA. O psicólogo na saúde pública: a busca de identidade. Assis: Faculdade de Ciências e Letras de Assis; 1995. [M imeo].

4. Amarante P. $\mathrm{O}$ homem e a serpente - outras histórias para a loucura e a psiquiatria. Rio de Janeiro: Fiocruz; 1996.

5. Amarante P. Manicômio e loucura no final do século e do milênio. In: Fernandes MI, Scarcelli IR, Costa ES, organizadores. Fim de século: ainda manicômios? São Paulo: IPUSP; 1999. p. 47-52.

6. Kinoshita RT. Em busca da cidadania. In: Campos FCCB, Henrique CM P, organizadores. Contra a maré à beira mar: a experiência do SUS em Santos. São Paulo: Hucitec; 1997. p. 67-77.

7. Costa-Rosa A. Saúde M ental comunitária. Análise dialética das práticas alternativas [dissertação]. São Paulo (SP): Universidade de São Paulo; 1987.

8. Costa-Rosa A. O modo psicossocial: um paradigma das práticas substitutivas ao modo asilar. In: Amarante $\mathrm{P}$, organizador. Ensaios - subjetividade, Saúde M ental, sociedade. Rio de Janeiro: Fiocruz; 2000. p.141-169.

9. Costa-Rosa A, Luzio CA, Yasui S. Atenção psicossocial - rumo a um novo paradigma na Saúde M ental Coletiva. In: Amarante P, coordenador. Archivos de Saúde M ental e Atenção Psicossocial. Rio de Janeiro: $\mathrm{Nau}$; 2003. p. 13-44.
10. Instituto Brasileiro de Geografia e Estatística. IBGE Cidades@. 2002. [acessado 2002 dez 12]. Disponível em: http://www.ibge.gov.br/cidadesat/default.php

11. Francisco IC. Psicologia clínica: Saúde M ental pública um jeito de pensar o contexto atual do atendimento psicológico à Saúde M ental pública de Assis - SP. [monografia] Assis (SP): Universidade Estadual Paulista; 1990.

12. Estado de São Paulo. Proposta de trabalho para equipes multiprofissionais em unidades básicas e em ambulatórios de Saúde M ental. Arquivos da Coordenadoria de Saúde M ental do Estado de São Paulo 1982; 43(Ed. esp).

13. Campos GWS. Saúde Paidéia. São Paulo: Hucitec; 2003.

14. Onocko Campos R. Clínica: a palavra negada - sobre as práticas clínicas nos serviços substitutivos de Saúde M ental. Saúde em Debate 2001; 25(58):98-111.

15. Pena R, Firmino G. Relatos da construção da Atenção Psicossocial em Assis: a oficina de sexualidade produzindo sentidos e singularidades. In: Congresso Brasileiro de Psiquiatria, 2002, Out 16-19; Florianópolis, SC. p. 145.

16. Guattari F, Rolnik S. Micropolítica: cartografias do desejo. 2a ed. Petrópolis: Vozes; 1986.

17. Santos M. O país distorcido. São Paulo: Publifolha; 2002.

18. Arretche M. Financiamento federal e gestão local de políticas sociais: o difícil equilíbrio entre regulação, responsabilidade e autonomia. Cien Saude Colet [periódico na Internet]. 2003, 8(2) [acessado 2003 set 15]. Disponível em: http://www.scielo.br/pdf/csc/ v8n2/a02v08n2.pdf

Artigo apresentado em 03/07/2007

Aprovado em 13/12/2007 